\title{
Evaluación de la Actividad Inmunomoduladora de Extractos Metanólicos y de Alcaloides de Berberis darwinii $H$. (Berberidaceae)
}

\author{
Evaluation of the Immunomodulatory Activity of Methanolic Extracts \\ and Alkaloids of Berberis darwinii H. (Berberidaceae)
}

Daniela Núñez R. ${ }^{1}$; Natalia Balboa P. ${ }^{2}$; Nelson Quilaqueo P. ${ }^{1}$; Marysol Alvear Z. ${ }^{2}$ \& Marco Paredes H. ${ }^{1}$

NÚÑEZ, R. D.; BALbOA, P. N.; QUILAQUEO, P. N.; ALVEAR, Z. M. \& PAREDES, H. M. Evaluación de la actividad inmunomoduladora de extractos metanólicos y de alcaloides de Berberis darwinii h. ( berberidaceae). Int. J. Morphol., 36(2):454-459, 2018.

RESUMEN: Berberis darwinii Hook es una especie que habita el sur de Chile y la Patagonia, utilizada por la etnia mapuche para el tratamiento de procesos inflamatorios, estados febriles y dolor de estomacal. El propósito del siguiente estudio fue evaluar in vitro las propiedades del extracto total y de alcaloides de raíz de $B$. darwinii sobre viabilidad celular y la translocación del factor nuclear NF-kB en línea celular RAW 264.7. Se observó que los extractos no afectan negativamente la viabilidad en las células e inhibieron la translocación del factor nuclear NF-kB asociado a la modulación de la inflamación solo frente al extracto total. Estos resultados indicarían que $B$. darwinii podría inhibir algunos mecanismos específicos de la defensa celular al modular la translocación de NF- kB.

PALABRAS CLAVE: NF-kB; Inmunofluorescencia; RAW 264.7; Citómetro de flujo.

\section{INTRODUCCIÓN}

El estudio de compuestos con actividad farmacológica sobre el sistema inmune es de gran interés por su potencial terapéutico en el tratamiento de diferentes patologías asociadas a inflamación. Entre ellas podemos destacar esclerosis múltiple, artritis reumatoide, displasia de cadera, entre otras, siendo cada vez más frecuentes (Gautam \& Jachak, 2009). Estas patologías generalmente son tratadas con corticosteroides y antinflamatorios no esteroidales (AINES), los cuales generan diversos efectos adversos a nivel digestivo, hepático y renal (Ortega Hernández-Agero, 2006). En la constante búsqueda de nuevos fármacos con actividad antiinflamatoria, los productos naturales nos brindan una gran diversidad de fitoquímicos, con un gran potencial biológico (Gómez Estrada et al., 2011). Dentro de estas especies encontramos a Berberis darwinii Hook, perteneciente a la familia Berberidaceae y al género Berberis, conocida comúnmente como Michay. Esta especie nativa habita el sur de Chile, desde la provincia de Ñuble hasta la Patagonia
(Hoffmann, 1982; Silva, 2010). Es un arbusto leñoso, espinoso, con flores de color amarillo y su fruto es una baya de color azul oscuro (Hoffmann). Esta especie ha sido utilizada por la etnia Mapuche, para teñir lana y piezas de alfarería, y como planta medicinal en caso de fiebre, inflamación y dolores estomacales (Houghton \& Manby, 1985). Este arbusto presenta tanto en tallos, frutos, hojas y raíces diversos tipos de fitoquímicos, destacándose la presencia de diversos alcaloides y polifenoles (Hoffmann; Muñoz et al., 2001). A pesar de sus diversos usos en la medicina tradicional del pueblo Mapuche y los amplios beneficios sobre la salud humana ya descritos para este género, su actividad biológica no ha sido descrita totalmente. El propósito del siguiente trabajo, fue evaluar in vitro el efecto de extractos metanólicos y de alcaloides obtenidos a partir de raíces de $B$. darwinii sobre la línea celular RAW 264.7 activadas con lipopolisacáridos sobre la viabilidad celular y la inhibición de la translocación del factor de transcripción NF$\mathrm{kB}$ asociado a la modulación del proceso inflamatorio.

\footnotetext{
${ }^{1}$ Depto. de Ciencias Básicas. Facultad de Medicina, Universidad de La Frontera, Temuco, Chile.

${ }^{2}$ Depto. de Ciencias Químicas y Recursos Naturales. Facultad de Ingeniería y Ciencias, Universidad de La Frontera, Temuco, Chile.
} 


\section{MATERIAL Y MÉTODO}

Material vegetal. Se utilizaron raíces de Berberis darwinii, recolectadas durante los meses de enero y febrero del 2014, en la localidad de Trakura, a $20 \mathrm{~km}$ de Icalma, en la provincia de Cautín, Región de la Araucanía, Chile (Altitud: 1298 (m.s.n.m.); GPS: -38 50.869', -71² 29.258'). El material vegetal fue transportado en condiciones de frío y oscuridad. Las raíces fueron trozadas, lavadas con agua destilada, y secadas durante 4 días a $40{ }^{\circ} \mathrm{C}$ en oscuridad para ser pulverizadas. La identificación taxonómica fue realizada por el Mg. Rubén Carrillo, Botánico de la Facultad de Ciencias Agropecuarias y Forestales de la Universidad de La Frontera. También se archivaron algunos ejemplares de Berberis darwinii en el Herbario Facultad de Ciencias Agropecuarias y Forestales de la Universidad de La Frontera bajo el código UFRO 300.

\section{Preparación de extractos metanólicos y alcaloides de} B. darwinii. Se utilizó $1 \mathrm{~g}$ de la muestra seca de raíz en 20 $\mathrm{mL}$ de metanol absoluto (3x) (grado analítico, Merck), las que se sometieron a sonicación, en un baño ultrasónico (Elmasonic, E 60H) durante $20 \mathrm{~min}$ a $0{ }^{\circ} \mathrm{C}$. A continuación, se centrifugaron, filtraron con papel Whatman $\mathrm{N}^{\circ} 1$ y concentradas a presión reducida (BÜCHI R-210) a punto de ebullición de $40^{\circ} \mathrm{C}$. Las muestras para obtención de alcaloides fueron resuspendidas en $20 \mathrm{~mL}$ de agua HPLC (Merck), en fase acuosa fueron basificadas hasta $\mathrm{pH} 12$ con $\mathrm{HCl} 1 \mathrm{M}$, y llevadas a un embudo de decantación. Se adicionaron $10 \mathrm{~mL}$ de $\mathrm{CHCl} 3$, recuperando la fase clorofórmica, este proceso se repitió hasta extraer todos los alcaloides desde la fase acuosa hacia el extracto clorofórmico, para esto se realizaron evaluaciones en la fase clorofórmica mediante cromatografía en capa fina y con el reactivo de Dragendorff. El contenido de alcaloides fue concentrado, eliminando el solvente mediante un rotavapor (HiTech, RE-52), con una temperatura de $40{ }^{\circ} \mathrm{C}$ y presión controlada. El concentrado fue masado y resuspendido en $1 \mathrm{~mL}$ de Dimetilsulfóxido (DMSO).

Línea celular, cultivo y tratamientos. Para los estudios in vitro, se utilizó la línea celular de macrófagos murinos RAW 264.7 (ATCC, USA). Las células se cultivaron en medio RPMI 1640 suplementado con $10 \%$ de suero fetal bovino y $0,1 \%$ de penicilina/estreptomicina/anfotericina B. a $37{ }^{\circ} \mathrm{C}$ con $5 \% \mathrm{CO} 2$ en cámara humedad. Las células se cosecharon mediante un raspado ligero, cuando se encontraban con una confluencia sobre el $75 \%$. Los tratamientos con extracto total y de alcaloides se realizaron a concentraciones de $0,1,1$, y $10 \mu \mathrm{g} / \mathrm{mL}$ durante 1 hora para todos los ensayos.
Evaluación de la citotoxicidad celular por citometría de flujo. Para estimar el efecto de los extractos sobre la viabilidad celular se realizó la tinción con yoduro de propidio (PI) $(0,5 \mathrm{mg} / \mathrm{mL})$ para ser evaluados por citometría de flujo. Para ello se prepararon cultivos de células $(2 \times 105 \mathrm{cel} / \mathrm{mL})$ en medio RPMI-1640 suplementado. Los cultivos se incubaron por 1 hora con los extractos metanólicos y de alcaloides $(0,1 \mu \mathrm{g} / \mathrm{mL}$ a $10 \mu \mathrm{g} / \mathrm{mL})$. Pasado este tiempo, las células fueron recuperadas mediante raspaje suave, centrifugadas $(700 \mathrm{~g})$ y resuspendidas en buffer fosfato salino (PBS) $1 \mathrm{X}$, e incubadas con $1 \mathrm{~mL}$ de PI durante 5 min antes de leer las muestras. La fluorescencia fue detectada utilizando un citómetro de flujo FACSCalibur (Becton Dickinson, CA, EEUU) equipado con óptica estándar. Las células fueron excitadas con un láser argón de longitud de onda de $488 \mathrm{~nm}$, empleando 100.000 células como mínimo en cada análisis. Los datos fueron trabajados en escala logarítmica y analizados utilizando el software Cell-Quest Pro (Becton Dickinson, CA, EEUU).

Evaluación de la distribución nuclear/citoplasmática de NF-kB. Para el análisis de NF-kB se realizó una suspensión celular $(2 \times 107 \mathrm{cel} / \mathrm{mL})$ sobre un portaobjeto con medio RPMI-1640 suplementado, activados con LPS (100 $\mathrm{ng} / \mathrm{mL}$ ) y tratados con extracto total y de alcaloides durante 1 hora. Finalizado el periodo de incubación, los cultivos fueron lavados 3 veces con PBS 1x durante 1 min cada uno. A continuación, las células fueron fijadas con metanol $100 \%$ durante 2 min y se secaron a temperatura ambiente durante 5 min. Para la detección inmunocitoquímica se utilizó el kit R.T.U Vectastain Universal ABC Kit (Vector Lab, No catalogo Cat PK-7200) con inmunoreactividad del $2^{\circ}$ anticuerpo Anti-Mouse IgG y Anti-Rabbit IgG, con modificaciones en el protocolo. A continuación, las células fueron incubadas con el anticuerpo primario anti-NFkB p65 (ThermoScientific) $(1: 250)$, durante toda la noche a $37^{\circ} \mathrm{C}$ en cámara húmeda. Luego se eliminó el exceso de anticuerpo realizando 3 lavados con PBS 1x por $5 \mathrm{~min}$, para luego aplicar el anticuerpo secundario AlexaFLuor 488 (1:250), por $30 \mathrm{~min}$ a $37^{\circ} \mathrm{C}$ en cámara húmeda. Se realizaron tres lavados con PBS 1x por $5 \mathrm{~min}$, para finalizar con el medio de montaje DAPI. Las imágenes fueron captadas con el microscopio Confocal láser de barrido (CLSM) Olympus Fluoview 1000, la emisión de fluorescencia se registró a excitación / emisión de $488 / 525 \mathrm{~nm}$.

Análisis estadístico. Para determinar si existen diferencias significativas entre las muestras, se realizó ANOVA de un factor y la prueba de comprobación de Dunnett's con un nivel de significancia del $95 \%$. Para el análisis estadístico se utilizó el programa Prisma 5.0 (GraphPad). 
RESULTADOS

Evaluación de citotoxicidad del extracto total y de alcaloides. La evaluación de citotoxicidad de los extractos sobre la línea celular RAW 264.7, indicó que los extractos poseen efectos de baja toxicidad en el rango de las concentraciones evaluadas sobre las células, presentando valores similares al control sin extracto (Figs. 1 y 2).
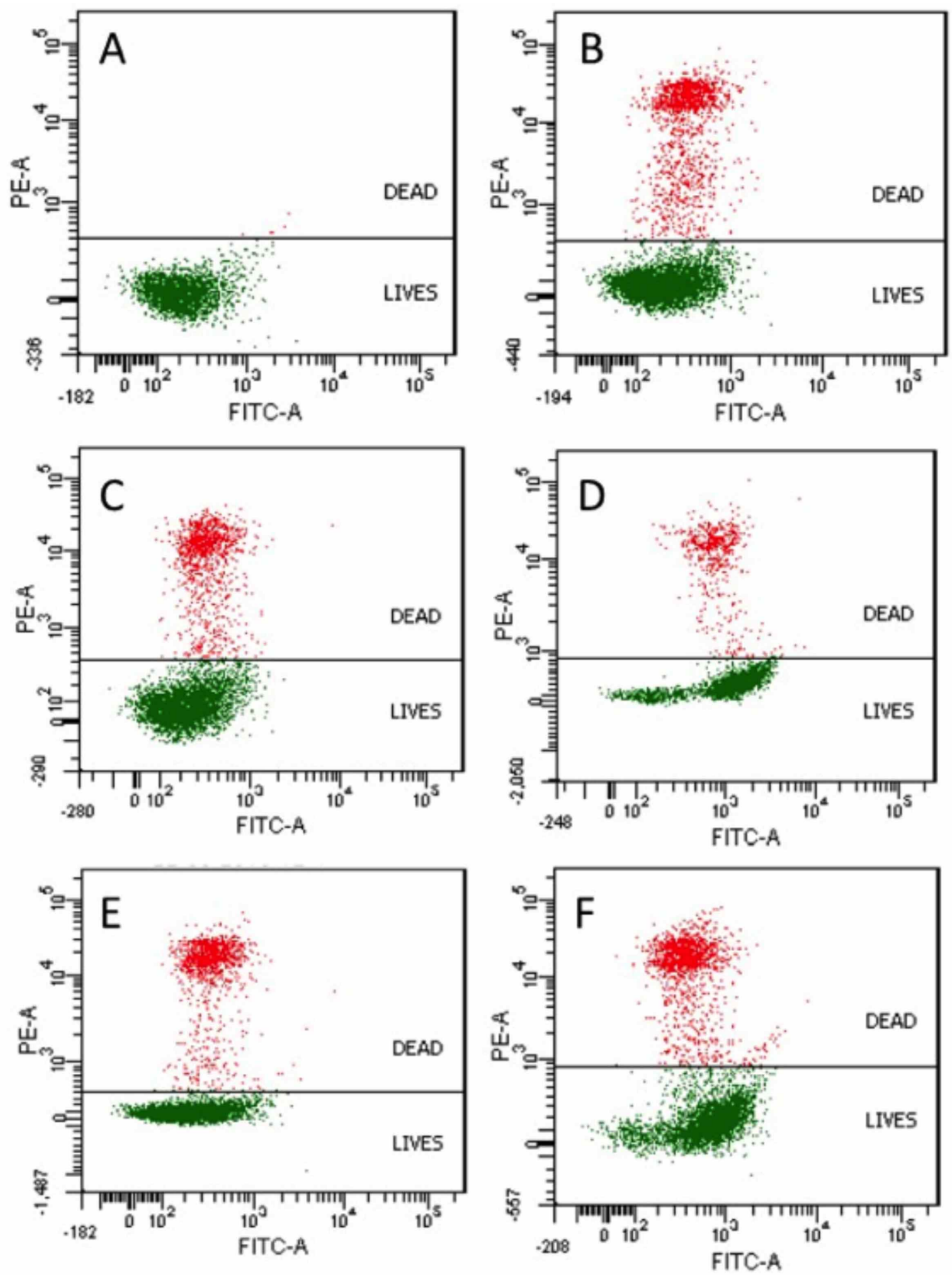

Fig. 1. Dot plots del análisis por citometría de flujo de celulas RAW 264.7 teñidas con PI y tratadas con extracto metanólico total y extracto de alcaloides de raíz de $B$. darwinii. A) Niveles de autofluorescencia de la población celular en estudio; B) Control de células sin tratamiento; C) Células con $0.1 \mathrm{mg} / \mathrm{mL}$ de extracto metanólico total; D) Células con $10 \mathrm{mg} / \mathrm{mL}$ de extracto metanólico total; E) Células con $0,1 \mathrm{mg} / \mathrm{mL}$ de extracto de alcaloides; F) Células con $10 \mathrm{mg} / \mathrm{mL}$ de extracto de alcaloides. 
Evaluación de la translocación de NF-kB. El análisis de NF-kB mediante inmunofluorescencia, indico la presencia del complejo proteico en todas las células fagocíticas presentes en los cultivos. Se pudo observar una marcada señal inmunoreactiva tanto en las células estimuladas por lipopolisacáridos, como en las células estimuladas y tratadas con los extractos a nivel nuclear (Fig. 3). Se observó una inhibición en la translocación del factor de transcripción dependiente de la concentración del extracto total (1 y $10 \mathrm{mg} / \mathrm{mL}$ ), observando inmunomarca a nivel citoplasmático. A diferencia de lo observado en los tratamientos con extracto de alcaloides, donde no se observó diferencia (Fig. 4).

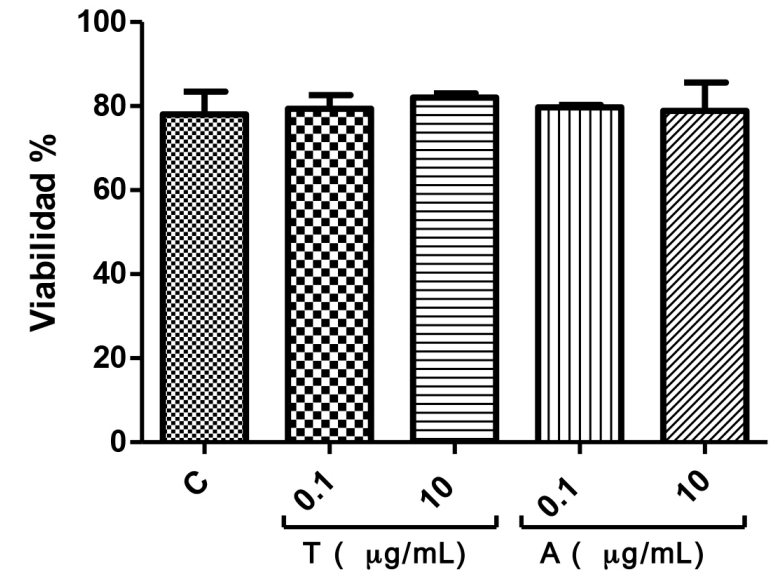

Fig. 2. Evaluación de citotoxicidad en línea celular RAW 264.7 tratadas con extractos de $B$. darwinii mediante evaluación de viabilidad por citometría de flujo con PI. Los valores son expresados como la media \pm S.D. (Control: Células sin tratamiento; $\mathrm{T}(\mu \mathrm{g} /$ $\mathrm{mL})$ : Extracto metanólico total; $\mathrm{A}(\mu \mathrm{g} / \mathrm{mL})$ : Extracto de alcaloides).
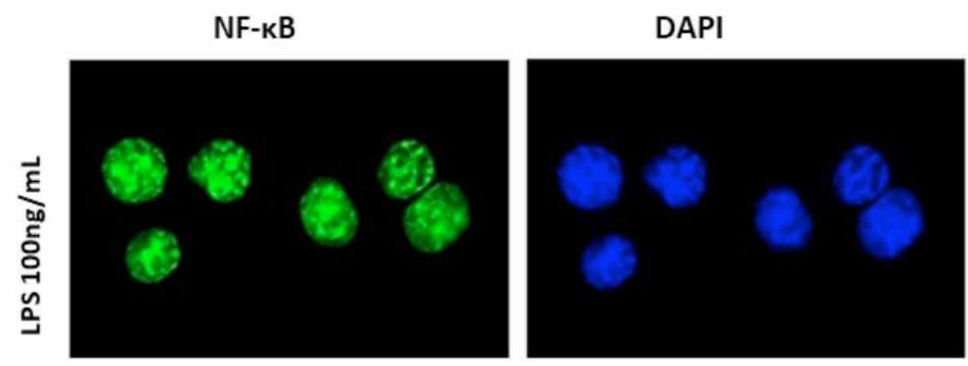

$\mathrm{NF}-\mathrm{Kb}+\mathrm{DAPI}$
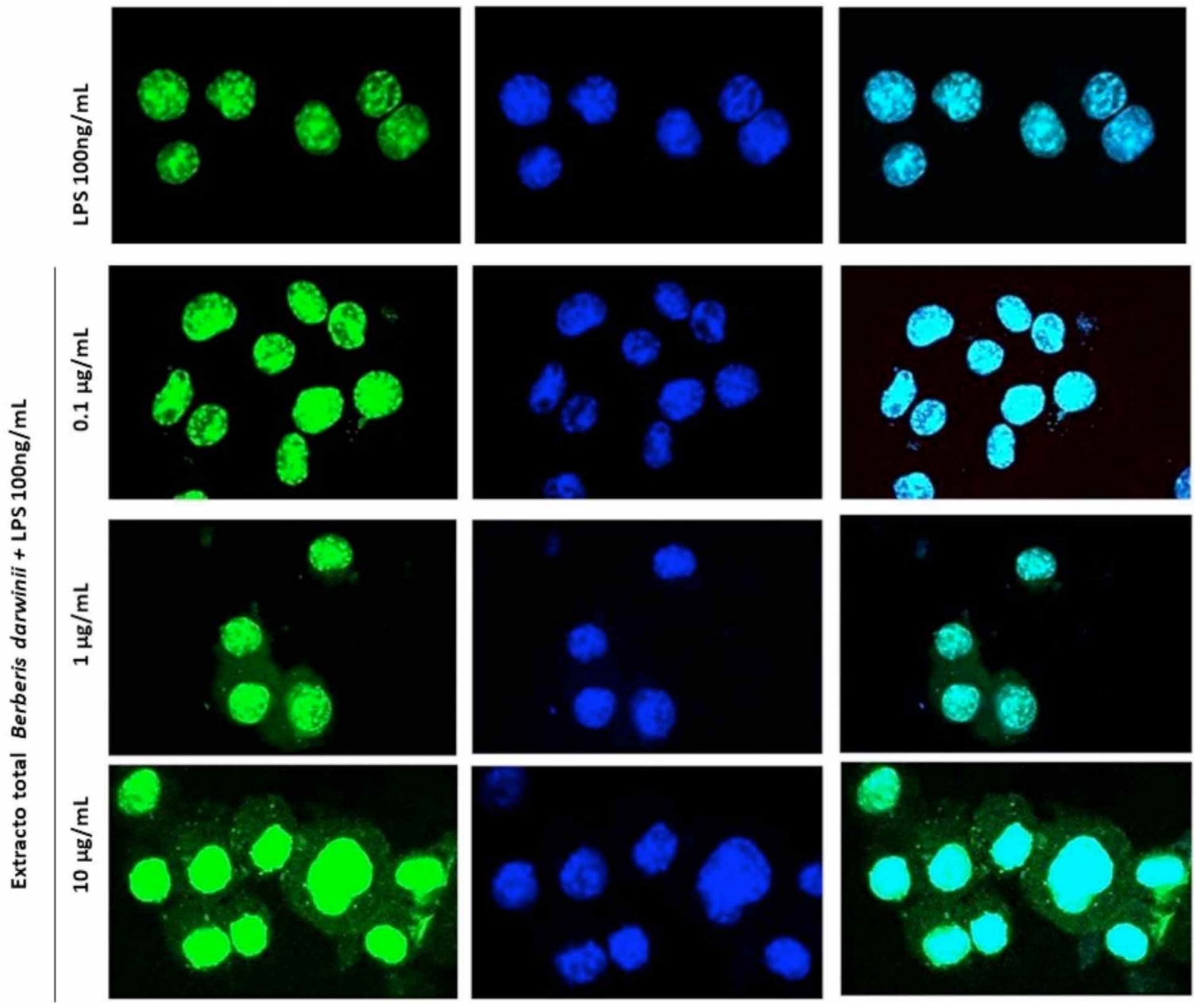

Fig. 3. Evaluación de la expresión del factor nuclear NF-kB mediante inmunofluorescencia en células RAW 264.7 estimuladas con LPS y tratadas con extracto metanólico total. (NF-kB: Factor de transcripción NF-kB marcado con AlexaFluor 488; DAPI: 4',6-diamino-2-fenilindol marcador fluorescente nuclear). 

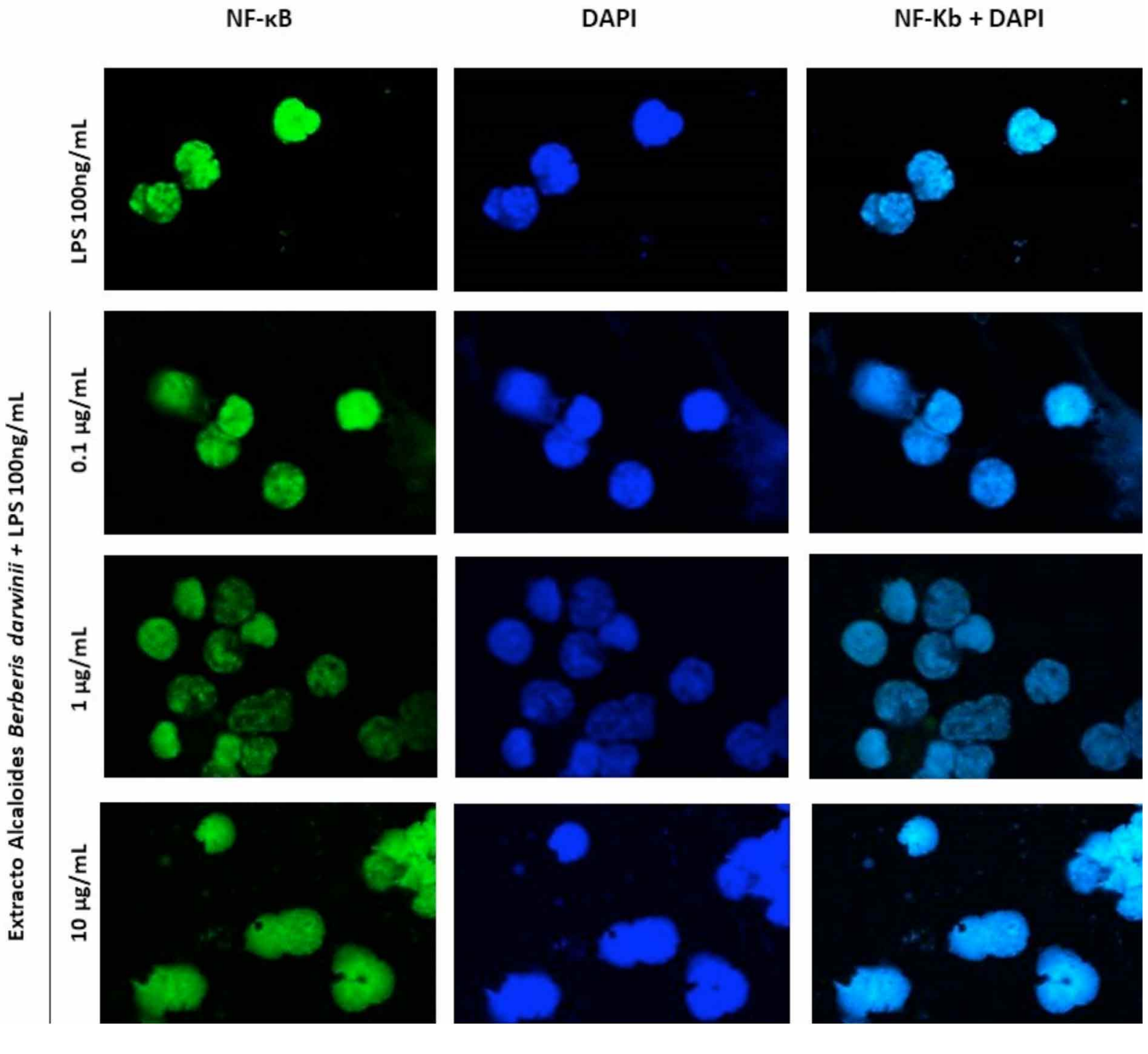

Fig. 4. Evaluación de la expresión del factor nuclear NF-kB mediante inmunofluorescencia en células RAW 264.7 estimuladas con LPS y tratadas con extracto de alcaloides (NF-kB: Factor de transcripción NF-kB marcado con AlexaFluor 488; DAPI: 4',6-diamino-2-fenilindol marcador fluorescente nuclear).

\section{DISCUSIÓN}

En la búsqueda de nuevos compuestos que presenten actividad antiinflamatoria, los productos naturales brindan una gran diversidad de fitoquímicos, destacando los alcaloides y polifenoles como parte de los grupos más diversos de metabolitos secundarios presentes en las plantas (Gómez Estrada et al.). Dentro del proceso inflamatorio, el factor NF-kB participa en la respuesta inmunitaria, tanto en el desarrollo, formación, progresión y apoptosis de diversos tumores. Este factor se encuentra como un precursor inacti- vo en el citoplasma, formando un complejo con la proteína inhibidora IkB (Echeverri \& Mockus, 2008). Esto permite que en presencia de algún patogeno como los lipopolisacaridos (constituyentes de la membrana externa de las bacterias Gram negativas), se active la vía de señalización mediante el receptor Toll-like 4, estimulando la fosforilación, ubiquitinización y degradación de las proteínas inhibitorias mediante el proteosoma, librando a NF-kB permitiendo su translocación al núcleo, modulando así la 
transcripción de la producción de citoquinas inflamatorias, proliferación y apoptosis en diversos tipos de células incluidos macrófagos (Habraken et al., 2001; Hsiang et al., 2005; Oeckinghaus \& Ghosh, 2009). Los resultados obtenidos en los ensayos de inmunofluorescencia indicarían que el extracto metanólico de raíz de $B$. darwinii estaría inhibiendo la translocación del factor nuclear kB (dosis dependiente), pudiendo modular así algunas respuestas en células RAW 264.7 asociadas al proceso inflamatorio, a diferencia de los extractos de alcaloides de B. darwinii, donde no se observó inhibición.

\section{CONCLUSIONES}

Los extractos totales de $B$. darwinii tendrían efecto sobre la modulación del factor nuclear kB en línea celular RAW 264.7. Esto sugiere que los extractos metanólicos podrían estar modulando ciertas vías asociadas con la actividad defensiva de estas células de forma selectiva, no así el extracto de alcaloides.

\section{AGRADECIMIENTOS}

Departamento de Ciencias Básicas, de Ciencias Químicas y Recursos Naturales y al BIOREN de la Universidad de La Frontera. Además, por la sustentación económica de la Beca Doctoral Nacional y Beca de Apoyo de tesis CONICYT N²1120557 y 21140816.

NÚÑEZ, R. D.; BALBOA, P. N.; QUILAQUEO, P. N.; ALVEAR, Z. M. \& PAREDES, H. M. Evaluation of the immunomodulatory activity of methanolic extracts and alkaloids of Berberis darwinii h. (berberidaceae). Int. J. Morphol., 36(2):454459, 2018 .

SUMMARY. Berberis darwinii Hook is a species that inhabits southern Chile and Patagonia, used by the Mapuche ethnic group for the treatment of inflammatory processes, febrile states and stomach pain. The purpose of the following study was to evaluate in vitro the properties of the total extract and alkaloids of the root of $B$. darwinii on cell viability and the translocation of the nuclear factor NF-kB in cell line RAW 264.7. It was observed that the extracts did not negatively affect the viability in the cells and inhibited the translocation of the nuclear factor $\mathrm{NF}-\mathrm{kB}$ associated with the modulation of inflammation only against the total extract. These results indicate that $B$. darwinii could inhibit some specific mechanisms of cell defense by modulating the translocation of NF-kB.

KEY WORDS: NF-Kb; Immunofluorescence; RAW 264.7; Flow cytometry.

\section{REFERENCIAS BIBLIOGRÁFICAS}

Echeverri, N. P. R. \& Mockus, I. S. Factor nuclear kB (NF-kB): signalosoma y su importancia en enfermedades inflamatorias y cáncer. Rev. Fac. Med, 56(2):133-46, 2008.

Gautam, R. \& Jachak, S. M. Recent developments in antiinflammatory natural products. Med. Res. Rev., 29(5):767-820, 2009.

Gómez Estrada, H. A.; González Ruiz, K. N. \& Medina, J. D. Actividad antiinflamatoria de productos naturales. Bol. Latinoam. Caribe Plantas Med. Aromat., 10(3):182-217, 2011.

Habraken, Y.; Piret, B. \& Piette, J. S phase dependence and involvement of NF-kappaB activating kinase to NF-kappaB activation by camptothecin. Biochem. Pharmacol., 62(5):60316, 2001.

Hoffmann, A. Flora Silvestre de Chile Zona Araucana. Santiago de Chile, Fundación Claudio Gay, 1982.

Houghton, P. J. \& Manby, J. Medicinal plants of the Mapuche. J. Ethnopharmacol., 13(1):89-103, 1985.

Hsiang, C. Y.; Wu, S. L.; Cheng, S. E. \& Ho, T. Y. Acetaldehydeinduced interleukin-1beta and tumor necrosis factor-alpha production is inhibited by berberine through nuclear factorkappaB signaling pathway in HepG2 cells. J. Biomed. Sci., 12(5):791-801, 2005.

Muñoz, O.; Montes, M. \& Wilkomirsky, T. Plantas Medicinales de Uso en Chile: Química y Farmacología. Santiago de Chile, Universidad de Chile, Vicerrectoría de Asuntos Académicos, Comité de Publicaciones Científicas, Editorial Universitaria, 2001. pp.61-4.

Oeckinghaus, A. \& Ghosh, S. The NF-kappaB family of transcription factors and its regulation. Cold Spring Harb. Perspect. Biol., 1(4):a000034, 2009.

Ortega Hernández-Agero, M. T. Plantas Medicinales para Enfermedades Reumáticas. Madrid, Universidad Complutense de Madrid, Ediciones Complutense, 2006. pp.27-38.

Silva, L. F. Flora Agropecuaria de Aysén. Aysén, Servicio Agrícola y Ganadero Región de Aysén 96, 2010.

Dirección para correspondencia:

Marco Paredes $\mathrm{H}$.

Universidad de La Frontera

Francisco Salazar 1145

Temuco

CHILE

Email: marco.paredes@ufrontera.cl

Recibido: 01-12-2017

Aceptado: 30-01-2018 